\title{
Antifungal activity of cotton fabrics finished modified silica-silver- carbon-based hybrid nanoparticles
}

Athor(s) 2018

Article reuse guidelines: sagepub.com/journals-permissions DOI: $10.1177 / 0040517518755792$ journals.sagepub.com/home/trj

SAGE

\author{
Igal Katerine', Arreche Romina A', Sambeth Jorge E', \\ Bellotti Natalia ${ }^{2}$, Vega-Baudrit José $\mathbf{R}^{3}$, \\ Redondo-Gómez Carlos ${ }^{3}$ and Vázquez Patricia $\mathbf{G}^{\mathbf{I}}$
}

\begin{abstract}
In this work, the one-pot sol-gel synthesis of novel siliceous matrixes doped with carbon from spent batteries is reported. The obtained solids with silver nitrate were characterized by their antifungal activity against Aspergillus sp., Cladosporium sp. and Chaetomium globosum, three well-known cellulolytic microorganisms responsible for the deterioration of cotton fabric. In this research it was possible to develop a methodology for the impregnation of cotton fabrics (brin type) and to evaluate the antifungal efficacy. Cotton fabric containing the highest amount of carbon showed the highest antifungal activity against $C$. globosum and Aspergillus sp. This may be because as the amount of carbon in the silica increases, there is an increase in the surface area that facilitates an effective distribution of the active phase to act, inhibiting the fungal growth.
\end{abstract}

\section{Keywords}

antimicrobial fabrics, carbon, silica, silver nitrate

Microorganisms can attach and grow on materials resulting in biofilm formation and corresponding biodeterioration under appropriate conditions. Cotton fabric bio-deterioration by microorganisms is considered harmful to human health, especially in healthcare centers where acquired infections are one of the leading causes of death. ${ }^{1-3}$ In this regard, there is a great interest in the development of antimicrobial textiles and polymers that are able to protect against all major pathogens. $^{4,5}$ As a result, several compounds have been studied due to their antimicrobial activity; particles based on metals, such as $\mathrm{Ag}, \mathrm{Cu}, \mathrm{Zn}$ and $\mathrm{Au}$, among others, have been used as coating in different materials, granting promising antimicrobial properties. $^{6-10}$ Several methods have been used to produce Ag nanoparticles, which are incorporated into matrices for specific applications. ${ }^{11,12}$

Cotton fabric modification by nanostructured coatings allows obtaining new materials, in which the properties of the bioactive particles are transferred to the fabric surface. Chitin, for instance, is a high molecular weight biopolymer whose poor water solubility represents its main drawback when applied in textile finishing (which is performed usually from aqueous media). ${ }^{13,14}$ The cotton fabrics were treated by using the pad-dry-cure process, which consists of the application of bioactive particle solution on cotton fabric by simple dipping, a quite successful strategy when it comes to adhesion and retention of original colors. ${ }^{15-17}$

Silver nanoparticles have shown antimicrobial activity against a wide range of microorganisms, and as a

'CINDECA - Centro de Investigación y Desarrollo en Ciencias Aplicadas "Dr. Jorge J. Ronco", (CCT-CONICET) UNLP, Argentina

${ }^{2}$ CIDEPINT - Centro de Investigación y Desarrollo en Tecnología de Pinturas (CIC-CONICET), Argentina

${ }^{3}$ LANOTEC - Laboratorio Nacional de Nanotecnología (CeNAT), Costa Rica

Corresponding author:

Dr Vázquez Patricia, CINDECA - Centro de Investigación y Desarrollo en Ciencias Aplicadas "Dr. Jorge J. Ronco", (CCT-CONICET) UNLP 1900 La Plata, Argentina La Plata, 1900 Argentina.

Email: vazquez@quimica.unlp.edu.ar 
consequence a vast number of works on silver nanoparticles can be found in the literature. ${ }^{18-24}$ The number of reports on green methodologies and bioactive plant-based products ${ }^{25}$ is interestingly growing. Other silver-based nanomaterials have been reported and their biological action mechanisms have been studied; a remarkable case is the one reported by Budama et al., ${ }^{26}$ who reported the fabrication of silver-containing reverse micelle cores of a (polystyrene)-block-(polyacrylic acid) copolymer synthesized by atom transfer free radical polymerization.

Exploring new strategies to integrate the antimicrobial activity of silver-based nanomaterials and the benefits it would bring into fabric modification is of special interest, as well as the possible incorporation of recycled waste materials. ${ }^{27,28}$ In this work a new methodology to reuse the materials contained in batteries as carbon and metal oxide containing matrixes is presented. Spent alkaline and zinc-carbon batteries were collected from CICPBA Campus in the City of La Plata, Argentina. Most of these batteries were AA size. ${ }^{29}$ The experimental methodology presented in this work complies mostly with the principles of Green Chemistry. ${ }^{30}$ The aim of this research is to obtain a siliceous matrix doped with carbon from waste batteries, which is also functionalized with 3-aminopropyltriethoxysilane (APTES) $)^{31,32}$ and impregnated with silver nitrate in order to obtain antimicrobial solids. The prepared solids were characterized by energy dispersive spectroscopy - scanning microscope microscopy (SEM-EDS), X-ray diffraction (XRD), Fourier transform infrared spectroscopy (FT-IR) and $\mathrm{N}_{2}$ adsorption-desorption $\left(\mathrm{S}_{\mathrm{BET}}\right)$. One of the synthesized solids was selected to finishing cotton fabrics by the pad-dry-cure method. ${ }^{33}$ Finally, the antifungal activity of this fabric was assessed against Aspergillus sp. and Chaetomium globosum, obtaining promising results.

\section{Experimental procedure}

\section{Synthesis of silica by the sol-gel method}

Synthesis of silica-carbon. It should be noted that the source of carbon was zinc-carbon batteries. These were first separated and then manually dismantled. Dismantling products such as plastic films, ferrous scrapes and paper pieces were discarded. ${ }^{29}$ The solids were obtained by the sol-gel method, under an $\mathrm{N}_{2}$ atmosphere. Tetraethylorthosilicate (TEOS) (Aldrich, $98 \%$ purity) was used as the precursor for silica, glacial acetic acid (AcH, Anedra) as the catalyst and absolute ethanol (EtOH, Baker 99.9\%) and distilled water as solvents. The TEOS $/ \mathrm{AcH} / \mathrm{EtOH} / \mathrm{H}_{2} \mathrm{O}$ molar ratios were 1:1:5:4, in all syntheses. During the gelation of the silica, certain amounts of carbon were incorporated
Table I. Nomenclature and composition of samples

\begin{tabular}{lc}
\hline NOMENCLATURE & SAMPLE COMPOSITION \\
\hline KHA & Pure silica \\
KIHA & Silica with $0.1 \%(w / w)$ of carbon \\
K2HA & Silica with $1.0 \%(w / w)$ of carbon \\
K3HA & Silica with $10.0 \%(w / w)$ of carbon \\
KHAf & Pure silica functionalized with \\
& APTES in I:I molar ratio \\
KIHAf & Silica with $0.1 \%(w / w)$ of carbon \\
& and functionalized with APTES \\
K2HAf & in I:I molar ratio \\
& Silica with I.0\%(w/w) of carbon \\
K3HAf & and functionalized with APTES \\
& in I:I molar ratio \\
KHAfAg & Silica with I0.0\%(w/w) of carbon \\
KIHAfAg & and functionalized with APTES \\
K2HAfAg & in I:I molar ratio \\
K3HAfAg & KHAf $+1 \%(w / w)$ of Ag \\
KHAf2Ag & KIHAf + I\% (w/w) of Ag \\
KIHAf2Ag & K2HAf $+1 \%(w / w)$ of Ag \\
K2HAfAg & K3HAf $+1 \%(w / w)$ of Ag \\
K3HAf2Ag & KHAf $+2 \%(w / w)$ of Ag \\
\hline
\end{tabular}

APTES: 3-aminopropyltriethoxysilane.

(Table 1). The carbon added, without treatment, was milled with a ball mill and then sieved with a mesh of 200. The obtained mixture was stirred for two hours and dry at room temperature for one week.

Functionalization with 3-aminopropyltriethoxysilane. In the second stage, a certain number of the samples of silica obtained $(1 \mathrm{~g})$ were contacted with a solution containing $25 \mathrm{~mL}$ of ethanol and $0.25 \mathrm{~mL}$ of APTES (Aldrich). All the components were stirred for $15 \mathrm{~min}$, then filtered and dried in flask at $100^{\circ} \mathrm{C}$. It is important to note that there was no carbon leaching.

Impregnation with silver nitrate. The samples were subsequently impregnated by the incipient wetness technique with silver nitrate (Aldrich 99.9\%), resulting in 1 and $2 \%(\mathrm{w} / \mathrm{w})$ of $\mathrm{Ag}$ in the dry solids.

\section{Characterization of the synthesized samples}

The acidic properties of the materials were assessed through a potentiometric titration with $n$-butylamine. The solid sample $(0.05 \mathrm{~g})$ was suspended in acetonitrile $(90 \mathrm{~mL})$ for $3 \mathrm{~h}$ and then titrated by adding $0.025 \mathrm{~mL} / \mathrm{min}$ of $n$-butylamine solution in acetonitrile $(0.05 \mathrm{~N})$ in 
a $\mathrm{pH} / \mathrm{mV} /{ }^{\circ} \mathrm{C}$ based on a microprocessor 211 Hanna Instruments $\mathrm{pH}$, using a combined $\mathrm{pH}$ electrode.

The nitrogen adsorption/desorption isotherms at $77 \mathrm{~K}$ of the solids were determined by using Micromeritics ASAP 2020 equipment. The solids were degassed for $700 \mathrm{~min}$ at $100^{\circ} \mathrm{C}$ and under $30 \mu \mathrm{m} \mathrm{Hg}$ vacuum. From the isotherms it was possible to determine the specific surface area $\left(\mathrm{S}_{\mathrm{BET}}\right)$.

XRD analysis was performed with a Philips model PW-1390 (control channel) and PW-1394 (motor control) chart recorder with built sweep. $\mathrm{Cu} \mathrm{K} \alpha$ radiation was used $(\alpha=1.5417 \AA)$, a nickel filter, $20 \mathrm{~mA}$ and

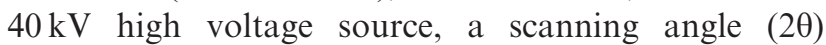
between $5^{\circ}$ and $60^{\circ}$, a scanning rate of $2^{\circ} / \mathrm{min}$ and amplitude of the vertical scale at 2000 counts/s.

FT-IR spectra were obtained using Bruker Vertex 70 equipment, including the sample in a $\mathrm{KBr}$ pellet (Aldrich, 99 wt\% FT-IR purity). Measurements were made in a range between 400 and $4000 \mathrm{~cm}^{-1}$. Two hundred scans were collected at a resolution of $4 \mathrm{~cm}^{-1}$ and averaged.

Scanning electron microscopy and energy dispersive spectroscopy (SEM-EDS) were used, SEM was performed to obtain solid micrographs using a Philips Model 505, working at a potential of $15 \mathrm{kV}$, on samples supported on graphite and gold. The images were obtained with an ADDAII acquirer with a Soft Imaging System.

\section{Assessment of antifungal activity}

The microorganisms used were Aspergillus sp., Chaetomium globosum and Cladosporium sp., which were selected based on their cellulolytic ability determined in agar plate assays. Both Aspergillus sp. and Cladosporium $s p$. were previously isolated from biodeteriorated fabrics by conventional microbiological techniques, while $C$. globosum belongs to the CIDEPINT culture collection. ${ }^{34}$ Subcultures of cited fungi were performed in Petri dishes. From these, the inoculums were obtained using a solution of $0.85 \% \mathrm{p} / \mathrm{v}$ $\mathrm{NaCl}$ and $0.005 \% \mathrm{p} / \mathrm{v}$ Tween 20 ; the concentration of the suspension was adjusted employing a Neubauer chamber to $10^{6}$ spores $/ \mathrm{mL}$. The composition of the culture medium used was $1.5 \mathrm{~g}$ agar Parafarm, $1 \mathrm{~g}$ dextrose (Anedra, analytical reagent), $0.5 \mathrm{~g}$ proteose peptone (OXOID), $0.1 \mathrm{~g} \quad \mathrm{KH}_{2} \mathrm{PO}_{4}$ (Anedra, analytical reagent), $0.05 \mathrm{~g} \quad \mathrm{MgSO}_{4} .7 \mathrm{H}_{2} \mathrm{O}$ (Anedra, analytical reagent) and distilled water. The agar plate assays were carried out at different silver concentrations of 60 and $120 \mathrm{ppm}$. The Petri dishes were inoculated in the center with $20 \mu \mathrm{L}$ of spore suspension with three fungi per triplicate. The plates were incubated at $28^{\circ} \mathrm{C}$ for 10 days. With the obtained results, the inhibition percentage (I\%) was calculated according to equation (1), where $C$ and $E$ correspond to the average diameter of each fungus in the control plate and on the plate with the tested solids, respectively. ${ }^{11,34}$ Three measurements of the fungal growth diameter were made in each plate and the standard deviation was determined

$$
\text { Inhibition }(\%)=[(C-E) / C] \times 100 \ldots
$$

\section{Finishing of cotton fabrics}

Based on the antifungal assessment, only the sample K3HAf2Ag was chosen to be applied on cotton fabric (brin type), using the pad-dry-cure method. ${ }^{15,33}$ The size of the cotton fabric used was $30 \mathrm{~mm} \times 30 \mathrm{~mm}$ (length $\times$ width). A sol consisting of 120 and $240 \mathrm{ppm}$ of sample with a reactive organic-inorganic binder was used. This method included full immersion at $20^{\circ} \mathrm{C}$ for $10 \mathrm{~min}$. Then, it was dried at $40^{\circ} \mathrm{C}$ for $2 \mathrm{~h}$ and finally cured for $1 \mathrm{~h}$ at $140^{\circ} \mathrm{C}$.

\section{Fabric antifungal activity assay}

The antifungal activity of the K3HAf2Ag-treated cotton samples was estimated against Aspergillus $s p$. and C. globosum according to the modified DIN 53931 standard method, using synthetic nutrient-poor agar (SNA), consisting of $1 \mathrm{~g}$ of $\mathrm{KNO}_{3}$ (Mallinckrodt, analytical reagent), $1 \mathrm{~g}$ of $\mathrm{KH}_{2} \mathrm{PO}_{4}$ (Anedra, analytical reagent), $0.5 \mathrm{~g}$ of $\mathrm{MgSO}_{4} \cdot 7 \mathrm{H}_{2} \mathrm{O}$ (Anedra, analytical reagent), $0.5 \mathrm{~g}$ of $\mathrm{KCl}$ (Cicarelli, pro-analysis), $0.2 \mathrm{~g}$ of saccharose (Anedra, analytical reagent) and $20 \mathrm{~g}$ of technical agar (Parafarm) per $1 \mathrm{~L}$ of distilled water. On each SNA plate, $100 \mu \mathrm{L}$ of a spore-suspension were spread. The inoculated plates were incubated at $29^{\circ} \mathrm{C}$, for $24 \mathrm{~h}$. Later, the cotton fibers samples $(30 \mathrm{~mm} \times 30 \mathrm{~mm})$ were placed on the medium and incubated at $29^{\circ} \mathrm{C}$ for 14 days. The degree of fungal growth was ordered in eight grades from 00 to 5 , as follows: (00) indicates no growth; 0 indicates fungal growth outside an inhibition zone surrounding the cotton specimen; (0) indicates fungal growth up to the edge of specimen; (1) indicates fungal growth only on and below the edge of the specimen; (2) indicates fungal growth on and below less than $25 \%$ of the specimen; (3) indicates fungal growth on and below $25-75 \%$ of the specimen; (4) indicates fungal growth on and below more than $75 \%$ of the specimen; and (5) indicates $100 \%$ overgrowth of the specimen. ${ }^{15}$

\section{Results and discussion}

Silica synthesized samples with different concentrations of carbon (Table 2) became homogeneously darker with increasing the amount thereof (Figure 1), maintaining a glassy gel structure in all cases. 
Figure 2 shows the Langmuir adsorption isotherms, Type I. This type corresponds to a monolayer adsorption. The amount adsorbed increases with $P$ until reaching a limit value corresponding to the coating of the surface by a monolayer. It is the characteristic isotherm of a chemisorption process only. The isotherms of this type correspond to microporous solids.

Table 2. Chemical composition, acid properties $\left(\mathrm{E}_{\mathrm{i}}\right)$ and $\mathrm{S}_{\mathrm{BET}}$ of the synthesized materials

\begin{tabular}{llll}
\hline Samples & {$[\mathrm{C}] \% \mathrm{~W} / \mathrm{W}$} & $\mathrm{E}_{\text {initial }}(\mathrm{mV})$ & $\mathrm{S}_{\mathrm{BET}}\left(\mathrm{m}^{2} / \mathrm{g}\right)$ \\
\hline KHA & 0 & 157.9 & 390.3 \\
KIHA & 0.1 & 148.3 & 338.1 \\
K2HA & 1.0 & 144.9 & 402.6 \\
K3HA & 10.0 & 129.2 & 457.6 \\
\hline
\end{tabular}

KHA: pure silica; KIHA: silica with $0.1 \%(w / w)$ of carbon; K2HA: silica with $1.0 \%(\mathrm{w} / \mathrm{w})$ of carbon; K3HA: silica with $10.0 \%(\mathrm{w} / \mathrm{w})$ of carbon.
The adsorption limit is determined, to a greater extent, by the accessible volume versus the pore size.

The isotherms of the solids are coincident and the $\mathrm{S}_{\mathrm{BET}}$ values correspond to the carbon aggregates. For the minimum amount of carbon (K1HA) there is a decrease in the surface area, which may be due to small agglomerates in the silica matrix. For the others two amounts of carbon (K2HA and $\mathrm{K} 3 \mathrm{HA}$ isotherms), the matrix diffusion silica $\mathrm{S}_{\mathrm{BET}}$ achieves an increase of solids (Figure 2).

In Figure 3, the FT-IR spectra exhibited bands of original silica and silica with different amounts of carbon content. The IR spectrum of silica (KHA) showed four absorption bands at around 1200, 1080, 800 and $460 \mathrm{~cm}^{-1}$, which are characteristic of this oxide. ${ }^{35}$ The bands at 1200 and $1080 \mathrm{~cm}^{-1}$ are assigned to asymmetric stretching modes of the $\mathrm{Si}-\mathrm{O}-\mathrm{Si}$ bond and the vibration at $800 \mathrm{~cm}^{-1}$ is associated with the symmetric stretching of the Si-O-Si bond or vibrational modes of ring structures. At lower wavenumber values,

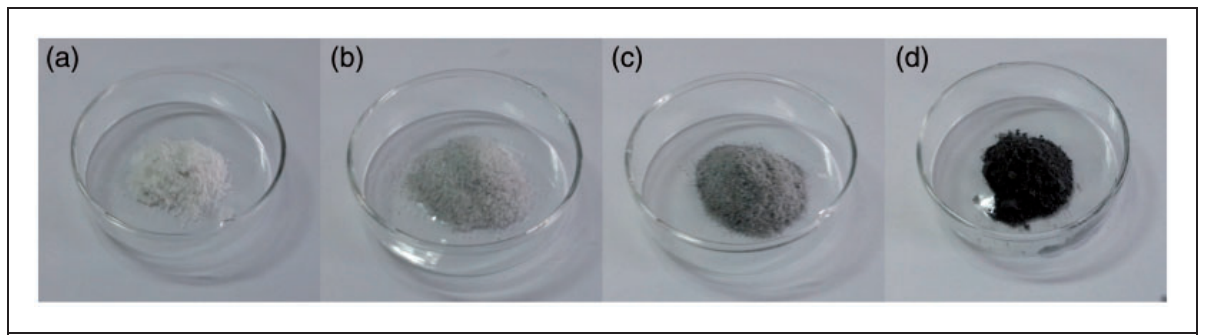

Figure I. Aspect of the synthesized samples: (a) pure silica; (b) silica with $0.1 \%(w / w)$ of carbon; (c) silica with I.0\% (w/w) of carbon; (d) silica with $10.0 \%(w / w)$ of carbon.

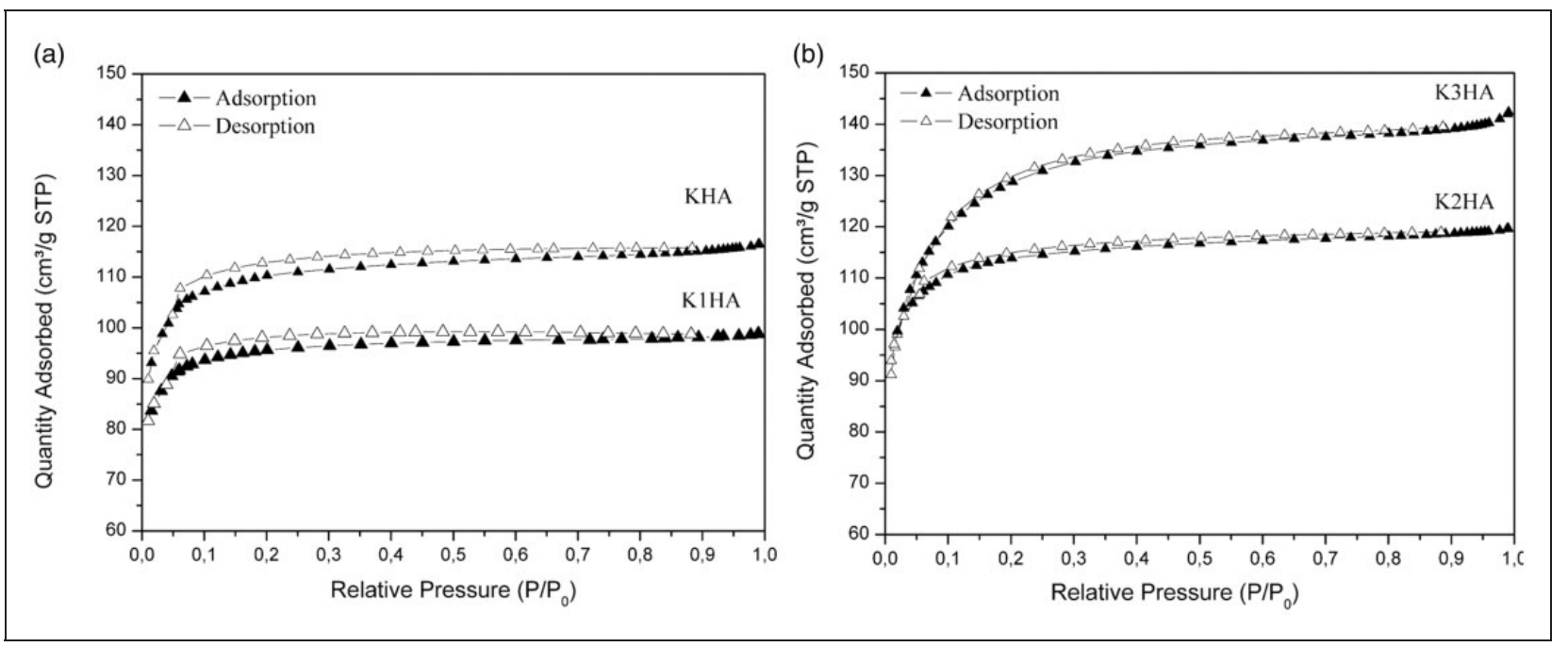

Figure 2. $\mathrm{N}_{2} / 77 \mathrm{~K}$ adsorption isotherms of (a) pure silica $(\mathrm{KHA})$, silica with $0.1 \%(\mathrm{w} / \mathrm{w})$ of carbon $(\mathrm{KIHA})$ and $(\mathrm{b})$ silica with $\mathrm{I} .0 \%$ $(\mathrm{w} / \mathrm{w})$ of carbon $(\mathrm{K} 2 \mathrm{HA})$, silica with $10.0 \%(\mathrm{w} / \mathrm{w})$ of carbon $(\mathrm{K} 3 \mathrm{HA})$. 


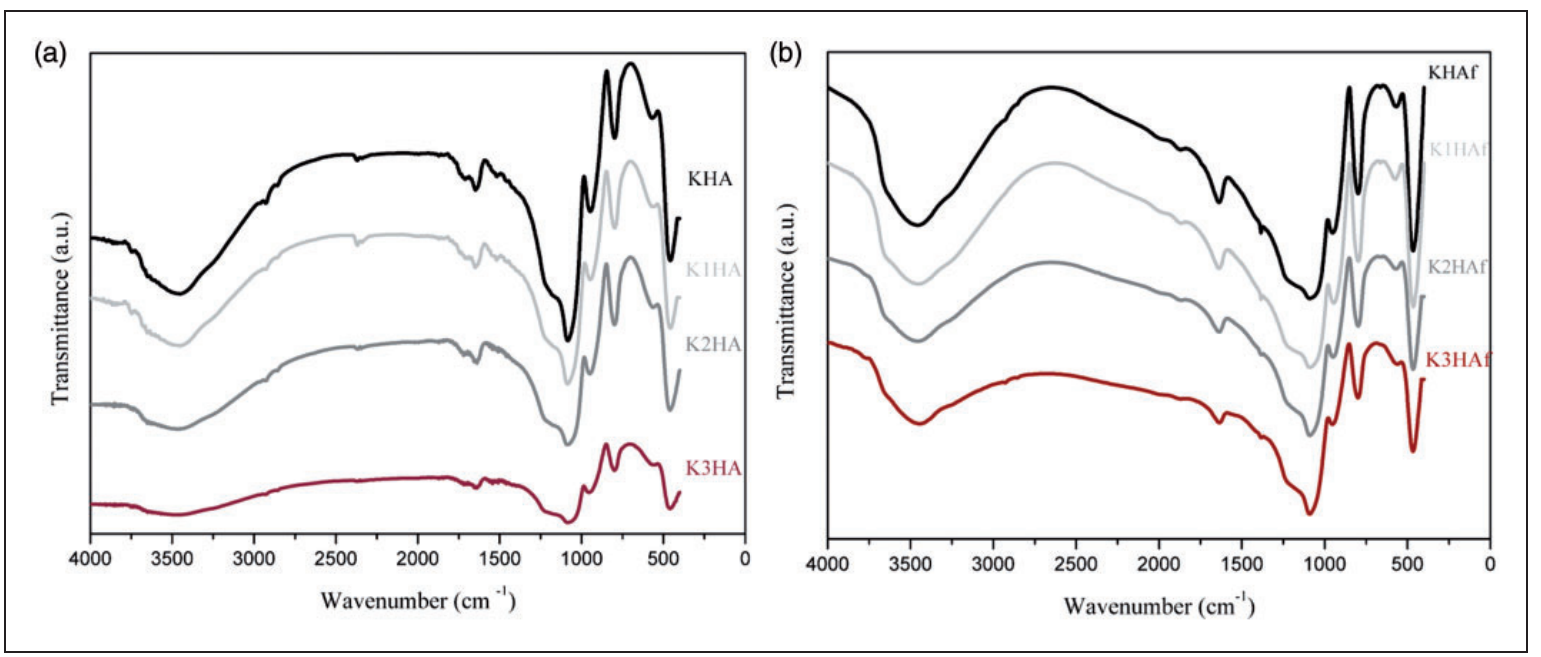

Figure 3. Fourier transform infrared spectrum of the synthesized samples: (a) pure silica (KHA), silica with $0.1 \%(w / w)$ of carbon $(\mathrm{KIHA})$, silica with $\mathrm{I} .0 \%(\mathrm{w} / \mathrm{w})$ of carbon $(\mathrm{K} 2 \mathrm{HA})$, silica with $10.0 \%(\mathrm{w} / \mathrm{w})$ of carbon $(\mathrm{K} 3 \mathrm{HA})$ and $(\mathrm{b})$ pure silica functionalized with 3aminopropyltriethoxysilane in I:I molar ratio (KHAf), silica with $0.1 \%(\mathrm{w} / \mathrm{w})$ of carbon and functionalized with 3-aminopropyltriethoxysilane in I:I molar ratio (KIHAf), silica with $1.0 \%(\mathrm{w} / \mathrm{w})$ of carbon and functionalized with 3-aminopropyltriethoxysilane in I:I molar ratio (K2HAf), silica with $10.0 \%(\mathrm{w} / \mathrm{w})$ of carbon and functionalized with 3-aminopropyltriethoxysilane in I:I molar ratio (K3HAf).

the $460 \mathrm{~cm}^{-1}$ band is assigned to the Si-O-Si bending mode, although it may be associated with defects caused by non-symmetric links. ${ }^{36}$

Three additional bands characteristic of silica obtained by the sol-gel technique, in the ranges 3600 3000,1640 and $950 \mathrm{~cm}^{-1}$, were observed. The characteristic broad band, in the range of $3600-3000 \mathrm{~cm}^{-1}$, is assigned to the stretching vibrations of water molecules with bridged-hydrogen bonds and silanol groups $(\mathrm{OH}$ and $\mathrm{SiO}-\mathrm{H})$ on the surface of the silica. ${ }^{37}$ The second band $\left(1640 \mathrm{~cm}^{-1}\right)$ is assigned to the molecular water deformation and this results from the angular deformations of $\mathrm{O}-\mathrm{H}$ in $\mathrm{H}_{2} \mathrm{O}(\mathrm{H}-\mathrm{O}-\mathrm{H})$. There is a small band near $1650 \mathrm{~cm}^{-1}$, which may be due to residual ethanol and, finally, the band centered around $950 \mathrm{~cm}^{-1}$ is assigned to the vibration of $\mathrm{Si}-\mathrm{OH}$ (silanols) bonds. ${ }^{37}$

The spectra of the silica samples with carbon show the same bands as the pure silica. This behavior may be due to the small amount of carbon that is included in each of them: K1HA, K2HA and K3HA, respectively (Figure 3(a)). These samples were functionalized with APTES to modify the surface of the silica, generating a chemical system related to ion exchange and, then, these solids are impregnated with $\mathrm{AgNO}_{3}$, giving antimicrobial character to the samples. According to Hinterwaldner et al. $^{38}$ and, as was done in this work, the mechanism of functionalization causes the rupture of the hydrogen bridges generated on the surface of the silica. This results in reactive silane groups subsequent to functionalization. According to previous studies, ${ }^{38}$ the average coating is close to 5 silane molecules $/ \mathrm{nm}^{2}$

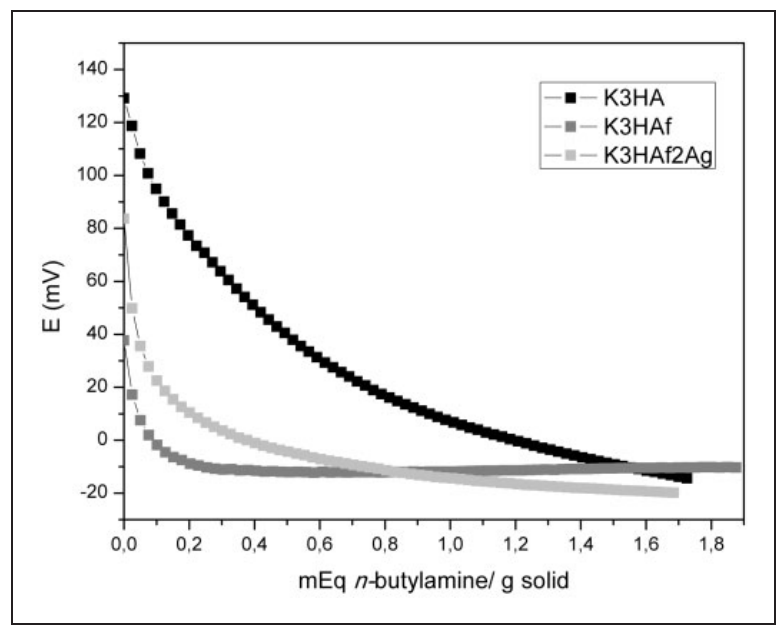

Figure 4. Potentiometric curves of the synthesized sample: silica with $10.0 \%(\mathrm{w} / \mathrm{w})$ of carbon $(\mathrm{K} 3 \mathrm{HA})$; silica with $10.0 \%(\mathrm{w} / \mathrm{w})$ of carbon and functionalized with 3-aminopropyltriethoxysilane in I:I molar ratio (K3HAf); $\mathrm{K} 3 \mathrm{HAf}+2 \%(\mathrm{w} / \mathrm{w})$ of $\mathrm{Ag}$ (K3HAf2Ag).

when acetone is added, but in any case the coating is never greater than $33 \%$ by the functionalizer. This result was also observed by our group in previous studies. ${ }^{31,32,38-40}$

There are no large variations in the bands; small shoulders in the region between 1750 and $1250 \mathrm{~cm}^{-1}$ can be associated with the methyl groups belonging to the APTES (Figure 3(b)). 
Regarding the acidic properties of the materials, for it to interpret the results using the technique of potentiometric titration it is known that potential initial electrode $\left(E_{i}\right)$ indicates the maximum acid strength of surface site values $(\mathrm{mEq} / \mathrm{g}$ solid), which when reaching a plateau indicates the total number of acid sites. In Table 2, the $\mathrm{E}_{\mathrm{i}}$ values show that the carbon has a value $E_{i}$ of $37.1 \mathrm{mV}$, while pure silica has an $E_{i}$ of $157.9 \mathrm{mV}$. The curves showed a substantial difference in the number of acid sites, indicating that compound impurity carbon could be of a basic nature. Hence, carbon samples have an $E_{i}$, which decreases with the amount of $\mathrm{C}$ in the silica matrix: 148.3, 144.9 and 129.2 $\mathrm{mV}$, respectively.

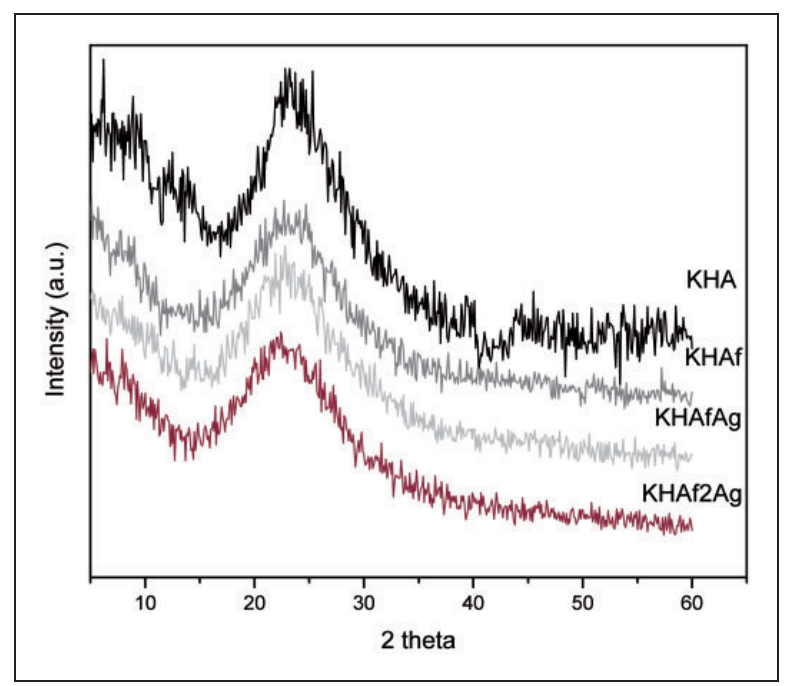

Figure 5. X-ray diffraction diagrams of the different samples. KHA: pure silica; KHAf: pure silica functionalized with 3-aminopropyltriethoxysilane in I:I molar ratio; KHAfAg: KHAf + I\% $(w / w)$ of $A g$; KHAf2Ag: KHAf $+2 \%(w / w)$ of $A g$.
Figure 4 shows the acidity in $\mathrm{K} 3 \mathrm{HA}$ during all the stages of the titration: pure, functionalized and impregnated with $\mathrm{AgNO}_{3}$. When this sample was functionalized, $\mathrm{E}_{\mathrm{i}}$ was $37.7 \mathrm{mV}$, in comparison with $\mathrm{K} 3 \mathrm{HA}$ with an $E_{i}$ of $129.2 \mathrm{mV}$ : an important decrease of the $E_{i}$ values was observed. When silver was incorporated, $\mathrm{E}_{\mathrm{i}}$ was $83.6 \mathrm{mV}$; this may be due to the relationship between the APTES groups and the silver ions.

The XRD diagrams of the samples are presented in Figure 5. These samples were synthesized at low ratio $\left[\mathrm{AgNO}_{3}\right] /[\mathrm{TEOS}]=0.008$ and calcination at $150^{\circ} \mathrm{C}$ was carried out. It could be for this reason that the wide peak of the amorphous silica is observed. ${ }^{41,42}$ The XRD patterns show for the silica with $0.01 \% \mathrm{C}$ sample, for all stages, a broad hump around $2 \Theta \sim 23$, typical of this material.

In relation to the morphology of the samples, the SEM micrographs show a typical particle corresponding to pure silica sheets (Figure 6(a)), while the silica containing most carbon (Figure 6(b)) also presents agglomerates, which could be attributed to the elements accompanying the carbon from disused batteries. This feature is observed before and after impregnation.

The antifungal assay results are presented in Figure 7. The three fungal strains were useful as biomarkers in the study, among them the most susceptible was Cladosporium $s p$.

The solid K3HAf2Ag (the one with highest carbon content) showed the most antifungal activity; this may be because that, as the amount of carbon in the silica increases, there is an increase in the surface area with a good pore size, which facilitates an effective distribution of the active phase to act inhibiting the fungi growth. Taking into account the results of the microbiological test, sample K3HAf2Ag was selected to be applied to the cotton fabric against the three fungal

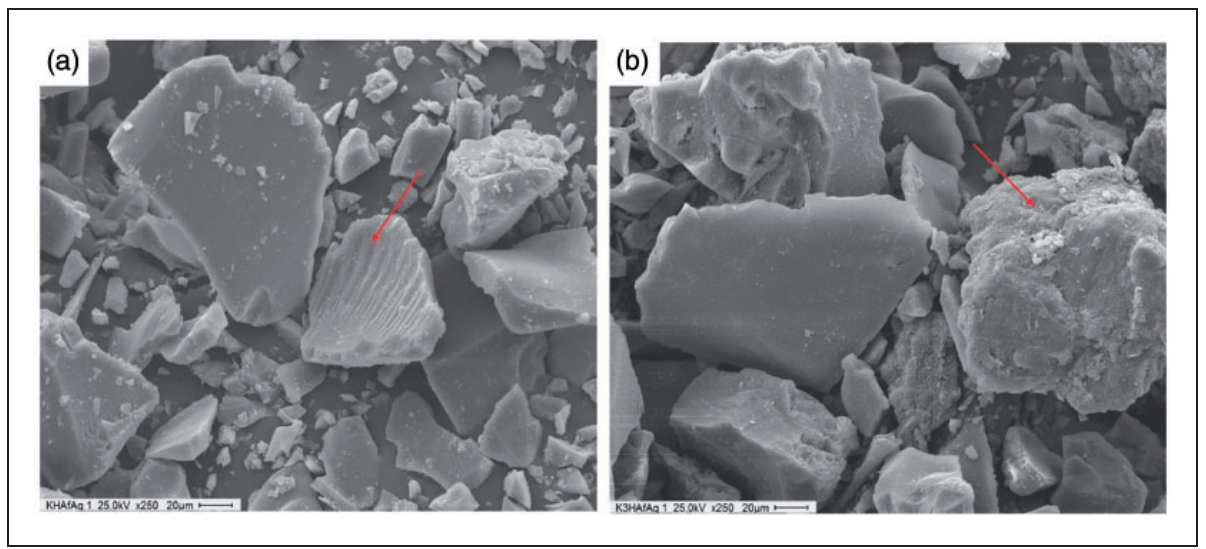

Figure 6. Scanning electron micrographs of (a) pure silica functionalized with 3-aminopropyltriethoxysilane (APTES) in I:I molar ratio $+1 \%(\mathrm{w} / \mathrm{w})$ of $\mathrm{Ag}$ and $(\mathrm{b})$ silica with $10.0 \%(\mathrm{w} / \mathrm{w})$ of carbon and functionalized with APTES in $\mathrm{I}: \mathrm{I}$ molar ratio $+1 \%(\mathrm{w} / \mathrm{w})$ of $\mathrm{Ag}$. Magnification: $250 \times$. 


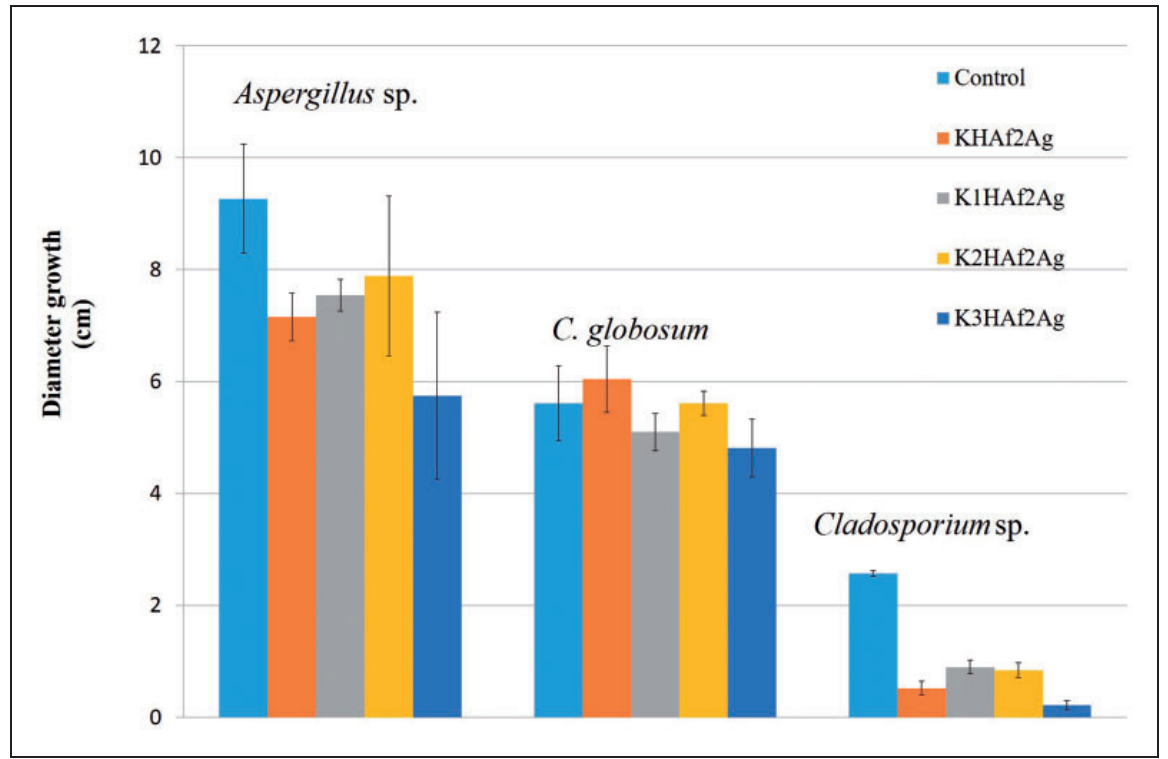

Figure 7. Diameter growth $(\mathrm{cm})$ of Aspergillus sp., C. globosum and Cladosporium sp. with the solids studied and the respective controls. KHAf2Ag: pure silica functionalized with 3-aminopropyltriethoxysilane in I:I molar ratio + $2 \%$ (w/w) of Ag; KIHAf2Ag: silica with $0.1 \%(\mathrm{w} / \mathrm{w})$ of carbon and functionalized with 3-aminopropyltriethoxysilane in I:I molar ratio + I\% (w/w) of Ag; K2HAf2Ag: silica with $\mathrm{I} .0 \%(\mathrm{w} / \mathrm{w})$ of carbon and functionalized with 3-aminopropyltriethoxysilane in I:I molar ratio + I\% (w/w) of Ag; K3HAf2Ag: silica with $10.0 \%(\mathrm{w} / \mathrm{w})$ of carbon and functionalized with 3-aminopropyltriethoxysilane in $\mathrm{I}: \mathrm{I}$ molar ratio $+\mathrm{I} \%(\mathrm{w} / \mathrm{w})$ of $\mathrm{Ag}$.

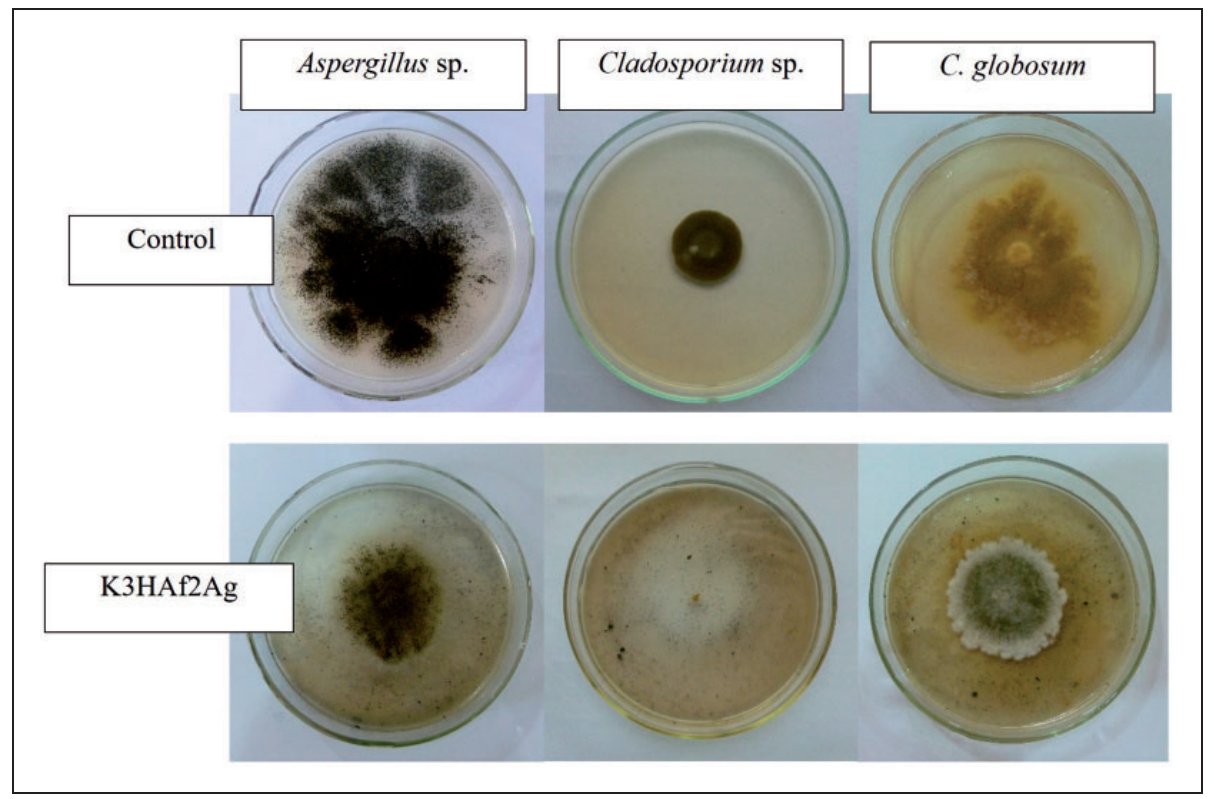

Figure 8. Photographs obtained from the microbiological test. K3HAf2Ag: silica with $10.0 \%(w / w)$ of carbon and functionalized with 3-aminopropyltriethoxysilane in I:I molar ratio $+1 \%(\mathrm{w} / \mathrm{w})$ of $\mathrm{Ag}$.

strains. Figure 8 presents the results of the antifungal activity assays with the selected solid to continue to the next stage.

Fabric antifungal activity assay was performed with two concentrations of $\mathrm{Ag}$ in the fabric, 120 and $240 \mathrm{ppm}$, but the best results were obtained with the highest Ag concentration. This confirmed the direct dependence of the inhibitory effect related to the $\mathrm{Ag}$ concentration on the cotton samples. Figure 9 shows the results obtained from the antifungal activity assay with the control and impregnated samples with the higher concentration of $\mathrm{Ag}$.

In relation to the whiteness of the fabrics used, the change of coloration was observed without measuring 


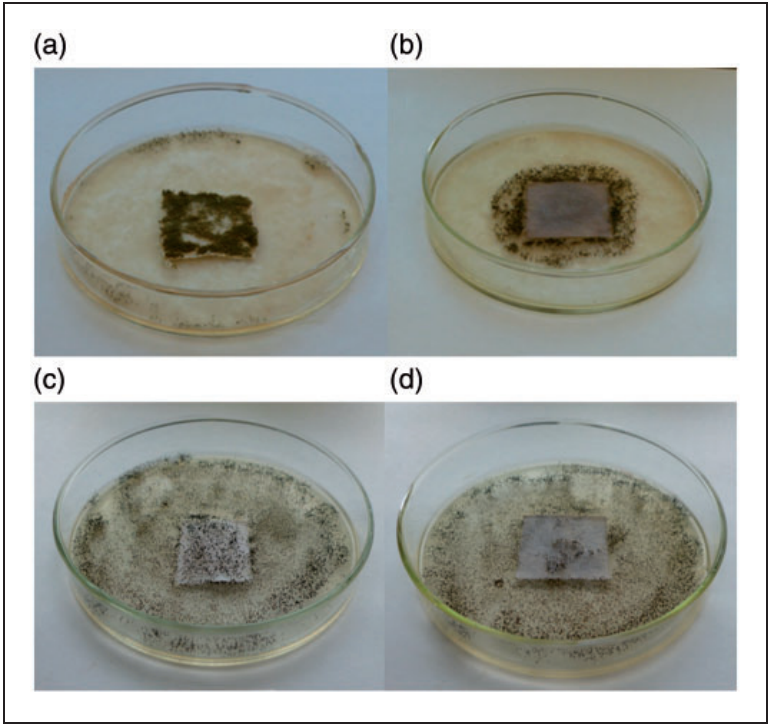

Figure 9. Assessment of the antifungal activity for cotton fabric with C. globosum without (a) and with silica with $10.0 \%(\mathrm{w} / \mathrm{w})$ of carbon and functionalized with 3-aminopropyltriethoxysilane in I:I molar ratio + I\% (w/w) of $\mathrm{Ag}(\mathrm{K} 3 \mathrm{HAf} 2 \mathrm{Ag})(\mathrm{b})$ and cotton fabric with Aspergillus sp. without (c) and with K3HAf2Ag (d).

equipment, only optically. From this observation, the fabrics containing carbon and silica suffered a slight coloration toward a darker white, for white as the original color. In the case of fabrics with solids containing silica, carbon and silver, a slightly brownish color could be observed from the Ag particles.

In the test with $C$. globosum, the cotton fabrics with K3HAf2Ag (Figure 9(b)) fully suppressed fungal growth on and below the cotton, but mycelium and ascomata developed well on the area of the nutrient medium surrounding the samples. The fungal growth was rated as less than $25 \%$, with grade 2 . Control fabrics showed an abundant fungal biofilm covering the entire surface (Figure 9(a)), with a high degree of development rated as grade 5. In the case of Aspergillus sp. the results are similar but there was increased growth over entire plate with both fabrics (Figure 9(c) and (d)). The samples with K3HAf2Ag were rated as grade 2 (Figure 9(d)), although the area covered with the fungal mycelium was higher than that presented by the fabrics inoculated with C. globosum (Figure 9(b)).

\section{Conclusion}

In this work, solids were synthesized including carbon from spent batteries, finding a path toward sustainability, helping to increase recycling processes. The fungal strains used for the bioassays are useful in evaluating the bioactivity of the materials, such as cotton cloth, because they cause great deterioration on them. In this research it was possible to develop a methodology for the impregnation of cotton fabrics (brin type) and to evaluate the antifungal efficacy of the synthesized solids. The cotton fabric containing the highest carbon amount showed the highest antifungal activity with $C$. globosum and Aspergillus sp. This may be because that, as the amount of carbon in the silica increases, there is an increase in the surface area, which facilitates an effective distribution of the active phase to inhibit the fungal growth.

The next steps to follow in this research consist of improving the synthesis of silica matrixes and so the antifungal efficiency in the final product. On top of this, new methods for impregnation on fabrics of different qualities will be tested.

\section{Acknowledgements}

The authors thank M Theiller for the SEM analysis, P Fetsis for $\mathrm{S}_{\mathrm{BET}}$ data and $\mathrm{L}$ Osiglio for the potentiometric determinations.

\section{Declaration of conflicting interests}

The authors declared no potential conflicts of interest with respect to the research, authorship and/or publication of this article.

\section{Funding}

The authors disclosed receipt of the following financial support for the research, authorship, and/or publication of this article: This work was supported by Universidad Nacional de La Plata (UNLP) and CONICET (PIP 003).

\section{References}

1. Mahltig B, Fiedler D and Botcher H. Antimicrobial solgel coatings. J Sol Gel Sci Technol 2004; 32: 219-222.

2. Neely A and Maley M. Survival of enterococci and staphylococci on hospital fabrics and plastics. $J$ Clin Microbiol 2000; 38: 724-726.

3. Ransjo U. Attempts to control clothes-borne infection in a burn unit. 2. Clothing routines in clinical use and the epidemiology of cross-colonization. J Hygiene Cambridge 1979; 82: 369-384.

4. El-Rafie MH, Ahmed HB and Zahran MK. Characterization of nanosilver coated cotton fabrics and evaluation of its antibacterial efficacy. J Carbohydr Polym 2014; 107: 174-181.

5. Liang J, Chen Y, Barnes K, et al. N-halamine/quatsiloxane copolymers for use in biocidal coatings. Biomaterials 2006; 27: 2495-2501.

6. Jaiswal S, McHale P and Duffy B. Preparation and rapid analysis of antibacterial silver, copper and zinc doped solgel surfaces. J Colloid Surface B 2012; 94: 170-176.

7. Jasiorski M, Leszkiewicz A, Brzezin S, et al. Textile with silver silica spheres: its antimicrobial activity against Escherichia coli and Staphylococcus aureus. J Sol Gel Sci Technol 2009; 51: 330-334.

8. Mahltig B, Fiedler D and Simon P. Silver-containing solgel coatings on textiles: antimicrobial effect as a function of curing treatment. $J$ Text Inst 2011; 102: 739-745. 
9. Mennig M, Schmitt $M$ and Schmidt H. Synthesis of Ag-colloids in sol-gel derived $\mathrm{SiO} 2$-coatings on glass. J Sol Gel Sci Technol 1997; 8: 1035-1042.

10. Çakır BA, Budama L, Topel Ö, et al. Synthesis of ZnO nanoparticles using PS-b-PAA reverse micelle cores for UV protective, self-cleaning and antibacterial textile applications. Colloids Surf A Physicochem Eng Aspects 2012; 414: 132-139.

11. Arreche RA, Hernández F, Blanco $M$, et al. Additive synthesis by sol-gel method for its use as antimicrobial. Procedia Mater Sci 2015; 8: 397-405.

12. Rai M, Yadav A and Gade A. Silver nanoparticles as a new generation of antimicrobials. Biotechnol Adv 2009; 27: $76-83$.

13. Vigo TL and Bruno JS. Fibers with multifunctional properties: a holistic approach. In: Lewin $\mathbf{M}$ and Preston $\mathbf{J}$ (eds) Handbook of Fibers and Science Technology, Vol. III, High Technology Fibers Part C. New York: Dekker, 1993, pp. 3-356.

14. Ali S, Joshi M and Rajendran S. Novel self-assembled antimicrobial textile coating containing chitosan nanoparticles. AATCC Rev 2011; 11: 49-55.

15. Tomšič B, Simončič B, Orel B, et al. Antimicrobial activity of $\mathrm{AgCl}$ embedded in a silica matrix on cotton fabric. J Carbohydr Polym 2009; 75: 618-626.

16. Nischala K, Rao TN and Hebalkar N. Silica-silver coreshell particles for antibacterial textile application. J Colloid Surface B 2011; 82: 203-208.

17. Koh E and Hong KH. Gallnut extract-treated wool and cotton for developing green functional textiles. Dyes Pigments 2014; 103: 222-227.

18. Zhang X-F, Liu Z-G, Shen W, et al. Silver nanoparticles: synthesis, characterization, properties, applications and therapeutic approaches. Int J Mol Sci 2016; 17: 1-34.

19. Abbasi E, Milani M, Fekri Aval S, et al. Silver nanoparticles: Synthesis methods, bioapplications and properties. Crit Rev Microbiol 2016; 42: 173-180.

20. Gudikandula K and Maringanti SC. Synthesis of silver nanoparticles by chemical and biological methods and their antimicrobial properties. J Exp Nanosci 2016; 11 : 714-721.

21. Song KC, Lee SM, Park TS, et al. Preparation of colloidal silver nanoparticles by chemical reduction method. Korean J Chem Eng 2009; 26: 153-155.

22. Suriati G, Mariatti M and Azizan A. Synthesis of silver nanoparticles by chemical reduction method: effect of reducing agent and surfactant concentration. International journal of automotive and mechanical engineering 2014; 10: 1920-1927.

23. Kim JS, Kuk E, Yu KN, et al. Antimicrobial effects of silver nanoparticles. Nanomed-Nanotechnol 2007; 3: 95-101.

24. Marambio-Jones $\mathrm{C}$ and Hoek EMV. A review of the antibacterial effects of silver nanomaterials and potential implications for human health and the environment. J Nanopart Res 2010; 12: 1531-1551.

25. Alemdar $\mathrm{S}$ and Agaoglu S. Investigation of in vitro antimicrobial activity of aloe vera juice. J Animal Vet $A d v$ 2009; 8: 99-102.
26. Budama L, Çakır BA, Topel Ö, et al. A new strategy for producing antibacterial textile surfaces using silver nanoparticles. Chem Eng J 2013; 228: 489-495.

27. Arreche R, Igal K, Bellotti N, et al. Síntesis verde y caracterización de sólidos de matriz silícea con cobre y plata obtenidos a partir de dos precursores para su aplicación como aditivos antifúngicos. Revista Materia 2015; 20: 612-620.

28. Palermo V, Igal K, Colombo Migliorero MB, et al. Valorization of different wastes and their use for the design of multifunctional eco-catalysts. Waste Biomass Valor 2017; 8: 69-83.

29. Gallegos MV, Falco LR, Peluso MA, et al. Recovery of manganese oxides from spent alkaline and zinc-carbon batteries. An application as catalysts for VOCs elimination. J Waste Manage 2013; 33: 1483-1490.

30. Anastas PT and Warner JC. Green Chemistry: Theory and practice. New York: Oxford University Press, 1998.

31. Arreche R, Blanco M and Vázquez P. Use of new silica fillers as additives for polymers used in packaging of fruit. Quim Nova 2012; 35: 1907-1911.

32. Arreche RA, Blanco M, Martín Martínez JM, et al. Structural synthesis of hydrophilic and hydrophobic silica for its use in food packaging films. Procedia Mater Sci 2012; 1: 572-579.

33. Mahltig B, Fiedler D, Fischer A, et al. Antimicrobial coatings on textiles-modification of sol-gel layers with organic and inorganic biocides. J Sol Gel Sci Technol 2010; 55: 269-277.

34. Bellotti N, Romagnoli R, Quintero C, et al. Nanoparticles as antifungal additives for indoor water borne paints. Prog Org Coat 2015; 86: 33-40.

35. Pakizeh M, Omidkhah MR and Zarringhalam A. Synthesis and characterization of new silica membranes using template-sol-gel technology. Int J Hydrogen Energ 2007; 32: 1825-1836.

36. Durán A, Serna C, Fornes V, et al. Structural considerations about $\mathrm{SiO} 2$ glasses prepared by sol-gel. J Non Cryst Solids 1986; 82: 69-77.

37. Orcel G, Phalippou J and Hench LL. Structural changes of silica xerogels during low temperature dehydration. J Non Cryst Solids 1986; 88: 114-130.

38. Hinterwaldner R, Glasel H, Hartmann E, et al. Hightemperature resistant polymerizable metal oxide particles. EP 1123354 A1, Germany, 1999.

39. Vega-Baudrit J, Navarro-Bañón V, Vázquez $\mathrm{P}$, et al. Addition of nanosilicas with different silanol content to thermoplastic polyurethane adhesives. Int $J$ Adhes Adhesiv 2006; 5: 378-387.

40. Vega-Baudrit J, Sibaja-Ballestero M, Vázquez $\mathrm{P}$, et al. Properties of thermoplastic polyurethane adhesives containing nanosilicas with different specific surface area and silanol content. Int J Adhes Adhesiv 2007; 27: 469-479.

41. Jie-Xin W, Li-Xiong W, Zhi-Hui W, et al. Immobilization of silver on hollow silica nanospheres and nanotubes and their antibacterial effects. Mater Chem Phys 2006; 96: 90-97.

42. Akkopru B and Durucan C. Preparation and microstructure of sol-gel derived silver-doped silica. J Sol Gel Sci Technol 2007; 43: 227-236. 